\begin{tabular}{llll} 
Abstract P228 Table 1 & & & \\
\hline Variable & STI positive & Control & p-value \\
\hline Non-consensual intercourse & $9.62 \%$ & $11.43 \%$ & 0.7606 \\
Other agencies involved & $46.15 \%$ & $40.00 \%$ & 0.4622 \\
School issues & $15.38 \%$ & $14.29 \%$ & 0.8546 \\
DSH/ED & $3.85 \%$ & $10.47 \%$ & 0.2611 \\
Alcohol misuse & $23.08 \%$ & $16.19 \%$ & 0.3073 \\
Drug misuse & $17.31 \%$ & $13.33 \%$ & 0.6069 \\
\hline
\end{tabular}

\section{P229 ARE CASES OF GONORRHOEA RISING IN VERY YOUNG PATIENTS IN SOUTH WEST LONDON? A RETROSPECTIVE CASE REVIEW OF PATIENTS AGED 18 YEARS AND YOUNGER DIAGNOSED WITH GONORRHOEA IN A LONDON TEACHING HOSPITAL GUM SERVICE}

Rachel Hill-Tout* , Katia Prime. St Georges NHS Trust, London, UK

\subsection{6/sextrans-2015-052126.273}

Background Cases of Gonorrhoea continue to rise in the UK and young people (YP) remain disproportionally affected despite efforts to reduce infection rates.

Aim To identify if there been a true rise in Gonorrhoea cases in very YP ( $\leq 18$ years) attending our GUM service.

Methods We identified all GUM (New and Rebook) attendances and Gonorrhoea diagnoses from 01/01/2011-31/12/2014 in patients $\leq 18$ from MILLCARE. Electronic records were reviewed for demographics, infection site (s), antimicrobial resistance, reinfection and Chlamydia co-infection.

Results

\begin{tabular}{|c|c|c|c|c|c|c|}
\hline & \multicolumn{3}{|c|}{$\begin{array}{l}\text { Number of GUM attendances } \\
\text { (\% of total annual GUM attendances) }\end{array}$} & \multicolumn{3}{|c|}{$\begin{array}{l}\text { Number of Gonorrhoea diagnoses } \\
\text { (\% of annual GUM attendances by } \\
\text { gender and total) }\end{array}$} \\
\hline & Male & Female & Total & Male & Female & Total \\
\hline 2011 & $111(22.0 \%)$ & $393(78.0 \%)$ & 504 & $0(0 \%)$ & $5(1.3 \%)$ & $5(1.0 \%)$ \\
\hline 2012 & $135(21.0 \%)$ & $508(79.0 \%)$ & 643 & $1(0.7 \%)$ & $16(3.1 \%)$ & $17(2.6 \%)$ \\
\hline 2013 & $482(21.5 \%)$ & $1764(78.5 \%)$ & 2246 & 7 (1.5\%) & 33 (1.9\%) & $40(1.8 \%)$ \\
\hline 2014 & 237 (19.5\%) & $980(80.5 \%)$ & 1217 & $7(3.0 \%)$ & $30(3.1 \%)$ & $37(3.0 \%)$ \\
\hline Total & 965 (20.9\%) & 3645 (79.1\%) & 4610 & $15(1.6 \%)$ & $84(2.3 \%)$ & $99(2.1 \%)$ \\
\hline
\end{tabular}

There were 99 Gonorrhoea diagnoses in 84 patients, 94/99 $(84.4 \%)$ in females and 15/99 (15.2\%) in males (5/15 (33.3\%) MSM). 1/84 (1.2\%) was HIV+ (MSM). 26/99 (26.2\%) infections were in White, 19/99 (19.2\%) in Caribbean/Mixed-Caribbean, 11/99 (11.1\%) in African/Mixed-African and 7/99 (7.1\%) in Other-Mixed ethnicities. 80/84 (95.2\%) were UK born. Age range was $15-18$.

$83 / 99$ (83.8\%) were genital and 12/99 (12.1\%) were multiple site infections. We found concurrent Chlamydia in 53/99 (53.3\%). Antimicrobial resistance was detected in 15/68 (22\%) culture + cases, $13 / 15(86.7 \%)$ in females and 2/15 (13.3\%) in MSM. 11/84 (13.1\%) patients had $\geq 1$ re-infection (positive test at $\geq 3$ months), 10/11 (90.9\%) females and 1/11 (9.1\%) MSM. Mean time to re-infection was 5.1 months.

Discussion NAAT testing was introduced into our service preceding the study period. We found Gonorrhoea diagnoses in patients $\leq 18$ have increased three-fold in 4 years in our clinic with high rates of Chlamydia co-infection, antimicrobial resistance and re-infection. MSM, females and patients of Black/ Mixed ethnicity are disproportionally affected. Further work is required to investigate factors contributing to the observed rise in Gonorrhoea in YP, and strategies to reduce infection rates.

\section{Category: Viral sexually transmitted infections}

\begin{tabular}{|c|c|}
\hline P230 & WITHDRAWN \\
\hline P231 & WITHDRAWN \\
\hline P232 & CASE REPORT: AN HIV POSITIVE PATIENT WHO HAS \\
\hline & $\begin{array}{l}\text { TWICE SPONTANEOUSLY CLEARED HEPATITIS C } \\
\text { INFECTION }\end{array}$ \\
\hline
\end{tabular}

Pippa Green*, S Ahmad. University Hospital of South Manchester, Manchester, UK

\subsection{6/sextrans-2015-052126.274}

Introduction A 26\% spontaneous clearance rate of Hepatitis C (HCV) in HIV negative populations is estimated, although the extent may be higher. Spontaneous clearance rates in HIV/HCV co-infected populations are lower. We report an HIV positive patient who has twice spontaneously cleared acute HCV infection.

Case report A 43 year old MSM diagnosed HIV positive in 1999 (WT virus, Nadir CD4 300) had evidence of past resolved Hepatitis A and B at time of HIV diagnosis. He commenced antiretroviral therapy (ARVs) in 2001 achieving virological suppression (VL $\leq 40)$. Hepatitis C was diagnosed in 2008 on tests prompted by raised LFTs: HCV antibody positive, HCV RNA $55 \mathrm{iu} / \mathrm{ml}$, genotype not available. HCV antibody was negative 12 weeks earlier. Seroconversion was asymptomatic and associated with a transient rise in serum alanine transaminase (peak 189). HCV RNA was undetectable 2 weeks later and remained so for 5 years. He re-presented with symptomatic acute Hepatitis $\mathrm{C}$ in 2013: HCV RNA $59258 \mathrm{iu} / \mathrm{ml}$, genotype 1, ALT 519. ALT normalised and HCV RNA fell to the limit of sensitivity of the assay (12 iu/ml) within 2 weeks. HCV RNA remained negative 1 year later. Re-infection occurred during a self imposed ARV treatment interruption and was associated with injecting drug use, high sexual risk taking behaviour and co-infection with bacterial STIs. Acute HCV was diagnosed within 4 weeks of restarting ARVs. Discussion As spontaneous clearance of $\mathrm{HCV}$ in HIV/HCV coinfected individuals is less common than those mono-infected, it is of interest that this patient has twice spontaneously cleared HCV.

\section{P233 IS ROUTINE BLOOD MONITORING FOR SUPPRESSIVE HERPES TREATMENT NECESSARY?}

Bridie Howe, Mei Liew, Stephen Bushby*, Robert Lapham, Jane Hussey. Department of Genito-Urinary Medicine, City Hospitals Sunderland, Sunderland, Tyne and Wear, UK

\subsection{6/sextrans-2015-052126.275}

Background There is no published evidence on the need for routine blood monitoring for people requiring daily oral acyclovir. Locally clinical practice differred between services. Dose reduction in moderate to severe renal impairment is recommended. Guidance for intravenous administration recommends measuring full blood count (FBC), renal (U\&E) and liver function (LFTs) periodically. 